\title{
Brachio-cephalic ('Gracz') fistula use for continuous hemofiltration in a hemodynamically unstable hemodialysis patient without venous vascular access: a case report
} Peter E Spronk*1,2,4, Jos NM Barendregt ${ }^{3}$, Guus Crooijmans ${ }^{3}$, Yolande M Vermeeren ${ }^{3}$ and Johannes H Rommes ${ }^{1}$

\author{
Address: ${ }^{1}$ Department of Intensive Care Medicine, Gelre Hospitals, Apeldoorn, The Netherlands, ${ }^{2}$ Department of Intensive Care Medicine, \\ Academic Medical Center, Amsterdam, The Netherlands, ${ }^{3}$ Department of Internal Medicine, Gelre Hospitals, Apeldoorn, The Netherlands and \\ ${ }^{4}$ Hermes critical care group, Amsterdam, The Netherlands \\ Email: Peter E Spronk* - p.spronk@gelre.nl; Jos NM Barendregt - j.barendregt@gelre.nl; Guus Crooijmans - g.crooijmans@gelre.nl; \\ Yolande M Vermeeren - y.vermeeren@gelre.nl; Johannes H Rommes - h.rommes@gelre.nl \\ * Corresponding author
}

\author{
Published: 30 June 2007 \\ Received: 3 April 2007 \\ Journal of Medical Case Reports 2007, 1:39 doi:I0.1 186/I752-1947-I-39 \\ Accepted: 30 June 2007 \\ This article is available from: http://www.jmedicalcasereports.com/content/I/I/39 \\ (c) 2007 Spronk et al; licensee BioMed Central Ltd. \\ This is an Open Access article distributed under the terms of the Creative Commons Attribution License (http://creativecommons.org/licenses/by/2.0), \\ which permits unrestricted use, distribution, and reproduction in any medium, provided the original work is properly cited.
}

\begin{abstract}
Even in patients with chronic renal failure and chronic intermittent hemodialysis, continuous venovenous hemofiltration $(\mathrm{CVVH})$ is the most often practiced renal replacement technique in the intensive care unit. Although patients show less hemodynamic instability during $\mathrm{CVVH}$ than during hemodialysis, it requires a blood flow exceeding $200 \mathrm{ml} / \mathrm{min}$ in the extracorporeal circuit necessitating the use of large bore catheters. Vascular access in critically ill septic and edematous patients is sometimes difficult, or even impossible.
\end{abstract}

We describe a technique of using a brachio-cephalic arterio-venous fistula in a hemodialysis patient for continuous hemofiltration (HF) resulting in improved hemodynamic stability.

\section{Background}

Even in patients with chronic renal failure and chronic intermittent hemodialysis (CIHD), continuous venovenous hemofiltration $(\mathrm{CVVH})$ is the most often practiced renal replacement technique in the intensive care unit (ICU) with a filtration rate of at least 2 liters/hour [1]. Patients show less hemodynamic instability during CVVH than during hemodialysis (HD) [2]. However, CVVH requires a blood flow exceeding $200 \mathrm{ml} / \mathrm{min}$ in the extracorporeal circuit implicating the use of large bore catheters. Obtaining or maintaining vascular access in critically ill septic and edematous patients is sometimes difficult, or even impossible.
We describe a technique of using a brachio-cephalic (BC) arterio-venous fistula in a hemodialysis patient for continuous hemofiltration resulting in improved hemodynamic stability.

\section{Case presentation}

A 58 year old caucasian male with renal insufficiency due to nephrosclerosis was admitted to the ICU with septic shock following bowel perforation. Previous renal replacement therapies had consisted of, in chronological order, continuous ambulatory peritoneal dialysis (CAPD) for 5 years ending with catheter removal due to bacterial peritonitis. Intermittent HD was then performed on central venous hemodialysis catheters, complicated by bilateral jugular thrombosis. Due to vessel usability, a classical 
Cimino fistula could not be constructed in the lower arm. Hence, a left-sided BC-fistula was constructed in the upper arm and successfully used for 1 year after which CAPD was resumed for 1 year. No signs of steel syndrome with hand ischemia occurred during the HD period [3]. The catheter was again removed when treatment was complicated by ultrafiltration (UF) failure and bacterial peritonitis. A history of massive vomiting, an abdominal CT-scan and pathological examination of a peritoneal biopsy taken upon removal of the catheter led to a diagnosis of encapsulating peritoneal fibrosis. Treatment for this disorder had been started with prednisolone and tamoxifen while intermittent HD was resumed on the well developed BC-fistula. Abdominal symptoms had practically been absent in the preceding two years.

Due to septic shock and hemodynamic instability, central venous access was needed for CVVH and vasopressor support besides other intravenous administrations. Because the left arm and subclavian vein were left untouched to spare the AV-fistula for future hemodialysis, CVVH was initiated on the left femoral vein while vasoactive medication was given on a right sided subclavian catheter. In spite of prophylactic administration of subcutaneous nadroparine 2850 IU daily, the patient developed a deep vein thrombosis of the left leg 1 week after admission, probably related to the large bore catheter for CVVH. Ultrasound examination confirmed the presence of a thrombus in the left common iliac vein. Further, intermittent fever and a purulent exit-site made the diagnosis of suspected catheter sepsis, after which the left femoral catheter was removed.

Frequent hemodialysis was performed but was complicated by hypotension in spite of the use of vasopressor support and this therapy failed to reverse the severe edematous state. In view of this clinical dilemma, we decided to try hemofiltration by vascular access to the existing brachio-cephalic fistula.

\section{Hemofiltration}

His shunt had been used for 3 years three times a week for intermittant HD without problems. Two large bore teflon canulas (15 Gz, Clampcath, Togo Medikit CO, Japan) were used to access the shunt for connection to the hemofiltration machine (Multifiltrate, Fresenius Medical Care, Germany). The clinical setting is depicted in figure 1 and 2. Subsequently, the normal CVVH protocol was used. Blood flow was started at $200 \mathrm{ml} / \mathrm{min}$ without volume extraction, substitution rate was set at $3000 \mathrm{ml} /$ hour. Anticoagulation was done systemically with unfractionated heparin aiming at an activated partial partial prothrombin time between 70-90 seconds in view of the thrombosis. Since hemodynamic parameters remained stable, blood flow was increased to $350 \mathrm{ml} / \mathrm{min}$, substitu- tion rate to $4500 \mathrm{ml} /$ hour, while fluid extraction was started as well. In the subsequent hours, UF rate could be increased to $500 \mathrm{ml} /$ hour without changes in hemodynamic measurements. After 12 hours of continuous hemofiltration, the canulas were removed to spare the AV fistula. In the following 14 days, the patient underwent daily continuous HF with an average volume extraction of 4.5 liters/day. In the mean time, his hemodynamic state had improved in such a way that we successfully switched to intermittent HD.

\section{Discussion}

We describe the use of a brachio-cephalic fistula for HFtreatment in a hemodynamically unstable patient with inaccessibility to the central venous compartment. In critically ill patients, the clinical application of continuous techniques like arteriovenous hemofiltration (CAVH) and intermittent HF have changed treatment modalities of renal failure which used to include only HD. To perform such treatments a reliable vascular access is of vital importance. Unfortunately, multiple vascular access problems are frequently seen among chronic HD or HF patients despite the reliability of the conventional arteriovenous fistula [4]. Since the introduction of large-bore catheters for acute HD, many problems with handling, material, and contamination of these catheters have been described. Nevertheless, catheterization of the femoral and jugular veins with a large-bore catheter has proved to be suitable as a rapid connection process for hemodialysis, hemofiltration, hemoperfusion, and plasmapheresis. In our patient, the femoral catheter had only been in place for 5 days, but thrombosis developed despite thrombosis prophylaxis. Prolonged femoral vein catheterization is a known risk factor of both the femoral and iliac veins

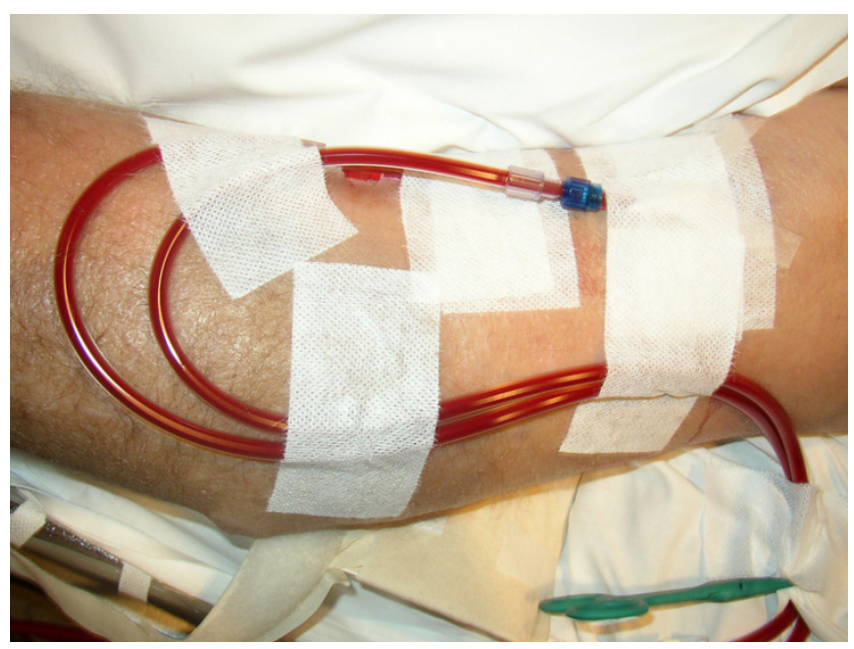

Figure I

large bore venflon catheters introduced into the arteriovenous fistula. 


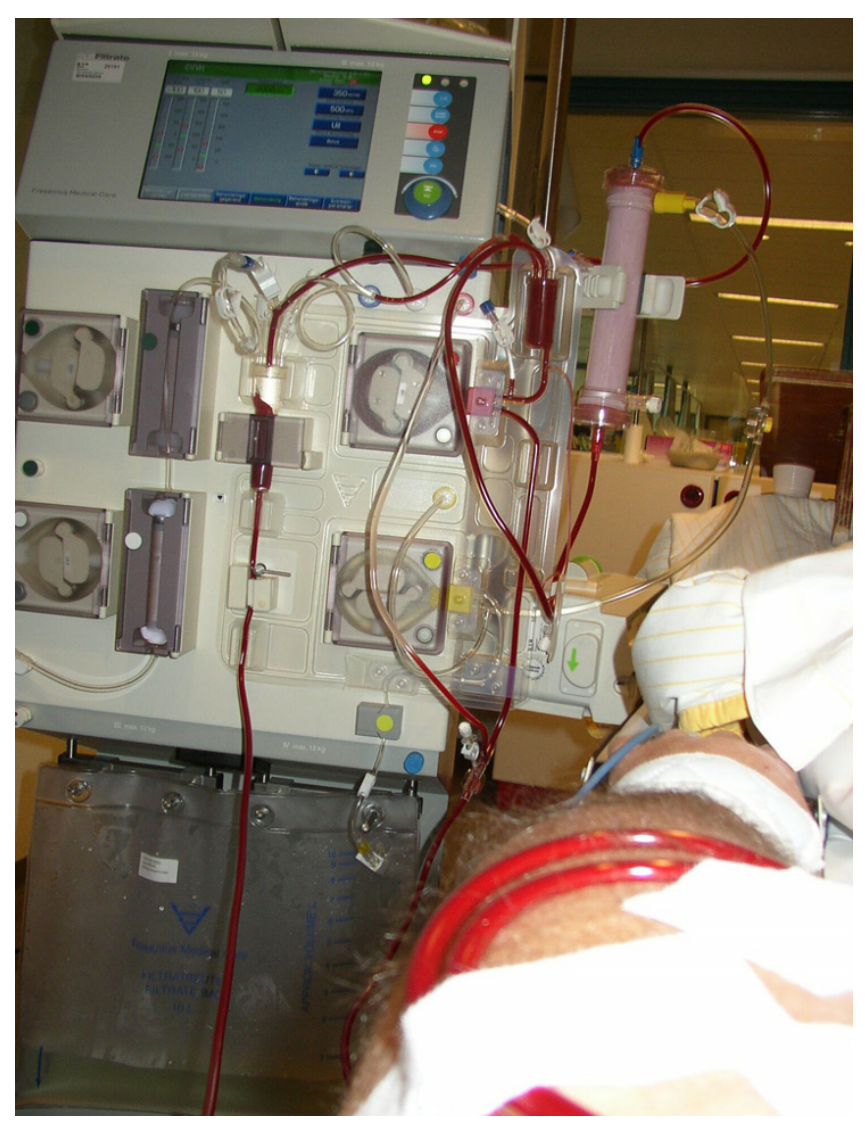

Figure 2

patient connected to hemofiltration machine.

thrombosis and stenosis [5]. Although a rising number of ICUs will use extra corporal citrate anticoagulation in unstable patients at risk for bleeding, many dialysis centers still use unfractionated heparine in those cases. The controle of heparinization (usually $2 \times$ normal value of aPTT) and reversibility of heparine overdose (protamine sulfate) are important potential advantages. Moreover, heparine given by the dialysis line may produce a higher local (femoral vein) heparine concentration with concurrent improved prevention of femoral/iliac vein thrombosis when compared to subcutaneous application of low molecular weight heparin analogues. Besides side-effects related to central venous catheters [6], obtaining or maintaining vascular access for continuous hemofiltration can sometimes be problematic, especially in the child or adult in multiple organ failure with edema and/or coagulopathy [7]. Ultrasound guidance for cannulation of the internal jugular and subclavian veins may be used. Nevertheless, common access problems include obstruction of the femoral, subclavian, or jugular veins due to previous thrombosis, insertion difficulties, safety concerns when cannulating the subclavian vein in coagulop- athy, and catheter and circuit occlusion due to disseminated intravascular coagulation.

Alarabi et al. describe a needleless prosthetic vascular access device (Hemasite) as an alternative solution in patients with high incidence of previous access failures, i.e. 1-8 failures per patient [8]. The 1 year cumulative survival rate of the device was 55\%, failure being caused predominantly by thrombosis. However, due to the clinical setting of our patient, this was not an option. One possible alternative to the chosen access strategy in this patient might have been the lumbar insertion of a vena cava catheter [9]. In our centre we have no practice with inserting and using these catheters and the use of such a catheter just proximal to an established venous thrombosis did not seem safe.

There are several risks in using the hemodialysis access for continuous renal replacement. Sparing the access site for future hemodialysis is a well recognized adagium in these patients. Severe bleeding from the access site can occur after needle displacement. Meticulous fixation of the needles and blood-lines was applied to prevent this complication. In spite of these measures we refrained from continuing treatment during nightly hours. However, this approach could have reduced the risk of damaging the access by frequent puncturing. Damaging by frequent puncturing would especially be a problem in a synthetic graft shunt. Infection of the access site however would still be a major concern in any prolonged treatment. Nevertheless, fistula needle insertion for 12 hours seems to be safe. The Tassin experience showed that long term hemodialysis sessions up to 10 hours with fistula cannulation did not produce additional problems with fistulas $[10,11]$.

\section{Conclusion}

While, for obvious reasons, we do not recommend the routine use of existing hemodialysis access for continuous treatment, it is important to realize that when no alternatives are feasible, like in our patient, the hemodialysis access can be used for delivering continuous or semi-continuous hemofiltration therapy in the intensive care unit.

\section{Competing interests}

The author(s) declare that they have no competing interests.

\section{Authors' contributions}

All authors contributed substantially to the manuscript. PES was involved in the primary care of the patient, conceived of the study, contributed to the interpretation and analysis of the data, and drafted the manuscript. JNMB revised the manuscript for intellectual content. GC was involved in the primary care of the patient and contributed to the interpretation of the data. YMV revised the 
manuscript for intellectual content. JHR conceived of the study, contributed to its design and the interpretation of the data, and revised the manuscript for important intellectual content. All authors approved the final version submitted for publication.

\section{Acknowledgements}

The patient consented to the publication of these findings to help improve patient care

\section{References}

I. Ronco C, Bellomo R, Homel P, Brendolan A, Dan M, Piccinni P, La Greca G: Effects of different doses in continuous veno-venous haemofiltration on outcomes of acute renal failure: a prospective randomised trial. Lancet 2000, 356:26-30.

2. Davenport A, Will EJ, Davidson AM: Improved cardiovascular stability during continuous modes of renal replacement therapy in critically ill patients with acute hepatic and renal failure. Crit Care Med 1993, 21:328-338.

3. Murphy G], White SA, Nicholson ML: Vascular access for haemodialysis. BrJ Surg 2000, 87:1300-1315.

4. Huber TS, Seeger JM: Approach to patients with "complex" hemodialysis access problems. Semin Dial 2003, 16:22-29.

5. Weyde W, Badowski R, Krajewska M, Penar J, Moron K, Klinger M: Femoral and iliac vein stenoses after prolonged femoral vein catheter insertion. Nephrol Dial Transplant 2004, 19:1618-1621.

6. Bambauer R, Inniger R, Pirrung KJ, Schiel R, Dahlem R: Complications and side effects associated with large-bore catheters in the subclavian and internal jugular veins. Artif Organs 1994, 18:318-321.

7. Dicarlo JV, Auerbach SR, Alexander SR: Clinical review: Alternative vascular access techniques for continuous hemofiltration. Crit Care 2006, 10:230.

8. Alarabi AA, Wahlberg J, Danielson BG, Tufveson G, Wadstrom J, Wikstrom B: Experience with the Hemasite device in haemodialysis and haemofiltration patients with vascular access problems. Nephrol Dial Transplant 1990, 5:508-5I2.

9. Matsagas MI, Gouva CD, Charissis C, Katopodis KP, Fatouros M, Kappas AM: Vascular access for haemodialysis in extreme situations: surgically placed inferior vena cava catheter. Nephrol Dial Transplant 2004, 19:752.

10. Innes A, Charra B, Burden RP, Morgan AG, Laurent G: The effect of long, slow haemodialysis on patient survival. Nephrol Dial Transplant 1999, 14:919-922.

II. Charra B: Is there a magic in long nocturnal dialysis? Contrib Nephrol 2005, 149:100-106.

\section{Publish with Biomed Central and every scientist can read your work free of charge}

"BioMed Central will be the most significant development for disseminating the results of biomedical research in our lifetime."

Sir Paul Nurse, Cancer Research UK

Your research papers will be:

- available free of charge to the entire biomedical community

- peer reviewed and published immediately upon acceptance

- cited in PubMed and archived on PubMed Central

- yours - you keep the copyright

Submit your manuscript here:

http://www.biomedcentral.com/info/publishing_adv.asp
BioMedcentral 